\title{
High Temperature Performance of SBS and LM-S Modified Asphalt Mixtures by Triaxial Test
}

\author{
Tang-Baoli ${ }^{1}$, Ren-yongqiang ${ }^{1 *}$, Chen-Xiangmei ${ }^{1}$, Hou-Huifang ${ }^{1}$, Liang-Jianping ${ }^{1}$ \\ ${ }^{1}$ Department of Civil Engineering, Ordos Institude of Technology, Ordos, Inner Mongolia, 017010, China.
}

\begin{abstract}
In order to study the high temperature performance of LM-S modified asphalt mixture and SBS modified asphalt mixture, repeated loading creep test was used to study the influence of temperature and deviatoric stress on the axial permanent deformation of the two kinds of asphalt mixture. At the same time, Permanent deformation, $\varepsilon @ 5000$, flow number FN and creep rate were select to evaluation of high temperature performance from different directions. The results show that the $\varepsilon @ 5000$ and creep rate are failed in the condition of high temperature and large deviatoric stress, so it has' $t$ widely practicable. The flow number FN is also limited by the conditions, which leads to the distortion of the flow number at lower temperature and smaller deviatoric stress so it is not easy to direct used as the evaluation index. Axial permanent deformation can reflect the permanent deformation in different cycles which is an excellent index to evaluate the high temperature performance of the two kinds of asphalt mixture, it is recommended to use axial permanent deformation to compare the LM-S modified asphalt mixture and SBS modified asphalt mixture The experimental results show that the axial permanent deformation of the LM-S modified asphalt mixture is always less than that of SBS modified asphalt mixture, it indicating that the high temperature rutting resistance of the LM-S modified asphalt mixture is better than that of SBS modified asphalt mixture.
\end{abstract}

\section{Introduction}

As one excellent modified asphalt mixture, SBS modified asphalt mixture, has always been favored by road workers. DaquanSuns research shows that SBS modified asphalt has very good anti-aging property and $\mathrm{Xu}$, Songs study also points out that SBS modified asphalt has great regeneration ability, and star type SBS is superior to linear type in high-temperature and anti-aging aspect ${ }^{[1]-[2]}$. But the SBS modified asphalt can only be used in middle and high class roads due to its high price, while a large number of middle and lower class roads still use base asphalt for the economical reason, which restricts SBS modified asphalt further development ${ }^{[3]-[4]}$. In order to solve the problems of SBS modified asphalt, such as easy segregation, high requirements in transportation and storage etc, the LM-S modified asphalt mixture which studied by road workers is the obtained corresponding asphalt mixture by dry-mixed. It could save investment cost greatly for no requirement of modified asphalt production equipment addition ${ }^{[5]}$. The modified asphalt mixture performance is stable, especially at hightemperature, which attracts more and more people' $\mathrm{s}$ attention $^{[6]}$. Wang Chaohui and others of Chang'an University compared the impact of different mixing methods on road performance through indoor tests. The results showed that the high-temperature performance of asphalt mixture produced by dry mixing method is better than that of asphalt mixture produced by wet mixing method. In order to compare the high-temperature performance of LM-S modified asphalt mixture and SBS modified asphalt mixture, and to find suitable hightemperature performance evaluation indicators, the following research is carried out.

\section{Test}

\subsection{Test materials}

\section{(1) Asphalt binder}

The subject research uses two types of asphalt binders: SBS modified asphalt and base asphalt. The basic performance of two asphalt binders both meets the "Highway Engineering Asphalt and Asphalt Mixture Test Regulations" (JTG E20-2011). The specific test results are shown in Table 1 below.

Table1. Technical indicators of asphalt binder

\begin{tabular}{cccc}
\hline & \multicolumn{2}{c}{ Test results } \\
Technical indicators & Unit & $\begin{array}{c}\text { SBS modified } \\
\text { asphalt }\end{array}$ & Asphalt \\
\hline Penetration $\left(25^{\circ} \mathrm{C}, 100 \mathrm{~g}\right.$, & $\begin{array}{c}0.1 \mathrm{~m} \\
\mathrm{~m})\end{array}$ & 65.3 & 85 \\
$\begin{array}{c}\text { Ductility }\left(5 \mathrm{~cm} / \mathrm{min}, \quad 5^{\circ} \mathrm{C}\right) \\
\geq\end{array}$ & $\mathrm{cm}$ & 28 & 16 \\
$\begin{array}{c}\text { Softening Point }), \geq \\
\left.\text { density (15 }{ }^{\circ} \mathrm{C}\right)\end{array}$ & ${ }^{\circ} \mathrm{C}$ & 56 & 50 \\
$\begin{array}{c}\text { Viscosity (135 } / \mathrm{cm}^{3} \\
\text { viscosity) }\end{array}$ & 1.031 & 1.028 \\
\hline
\end{tabular}

First author: TANG Baoli(1980-), male, master degree, lecturer.

*Correspondent author: Ren-yongqiang, master degree, senior engineer.E-mail:ryongqiang@oit.edu.cn 


\section{(2) Mineral aggregate}

The coarse aggregate used in the subject research is basalt, the fine aggregate is limestone machine-made sand, and the ore powder is finely ground from limestone. The basic performance index of the mineral also meets the requirements of the "Highway Engineering Aggregate Test Regulations" (JTG E42-2005). The test results are shown in Table 2, Table 3 and Table 4

Table2. Technical indicators of Coarse aggregate

\begin{tabular}{ccc}
\hline Technical indicators & Requirements & Test results \\
\hline Water absorption/\% & $\leq 2.0$ & 0.65 \\
Robustness/\% & $\leq 12.0$ & 5.2 \\
Apparent relative & $\geq 2.60$ & 2.849 \\
density/ $\left(\mathrm{g} / \mathrm{cm}^{3}\right)$ & Five grade & Five grade \\
Adhesion &
\end{tabular}

Table3. Technical dicators of fine aggregate

\begin{tabular}{ccc}
\hline Technical indicators & Requirements & Test results \\
\hline Mud content $/ \%$ & $\leq 2.0$ & 0.65 \\
Robustness $\%$ & $\leq 12.0$ & 5.2 \\
Apparent relative density/ & $\geq 2.60$ & 2.849 \\
$\left(\mathrm{~g} / \mathrm{cm}^{3}\right)$ & & \\
\hline
\end{tabular}

Table4. Technical dicators of Mineral powder

\begin{tabular}{cccc}
\hline $\begin{array}{c}\text { Technical } \\
\text { indicators }\end{array}$ & \multicolumn{2}{c}{ Requirements } & Test results \\
\hline $\begin{array}{c}\text { Apparent density/ } \\
\left(\mathrm{g} / \mathrm{cm}^{3}\right)\end{array}$ & \multicolumn{2}{c}{2.5} & 2.702 \\
Water content/\% & \multicolumn{2}{c}{1} & 0.8 \\
Particle size & $<0.6$ & 100 & 100 \\
\cline { 2 - 4 } range/\% & $<0.15$ & $90 \sim 100$ & 98 \\
& $<0.075$ & $75 \sim 100$ & 95 \\
Appearance & Non-agglomerated & Non- \\
Hydrophilic & \multicolumn{2}{c}{$<1$ aggerated } \\
coefficient & \multicolumn{2}{c}{$<1$} & 0.6 \\
Plasticity index/\% & \multicolumn{2}{c}{$<4$} & 2.3 \\
Heating stability & \multicolumn{2}{c}{ Recorded } & No deterioration \\
\hline
\end{tabular}

\subsection{Test method}

\section{(1) Test plan}

Add modifier LM-S in the mixing process of base asphalt and aggregate to produce LM-S modified asphalt mixture (dry mix), SBS modified asphalt mixture still adopts conventional production methods. Adopt Marshall design method for mix design.

Table5. Program of test

\begin{tabular}{cc}
\hline Equipments & CONTROL UTM-100 \\
Preload $/ \mathrm{KPa}$ & 20 \\
Load mode and waveform & $\begin{array}{c}\text { Loading } 0.1 \mathrm{~s} \text { and unloading } \\
0.9 \mathrm{~s} \text {, half sinusoid } \\
\text { intermittent loading }\end{array}$ \\
Confining pressure $/ \mathrm{KPa}$ & 138 \\
Deviatoric stress $/ \mathrm{Mpa}$ & $0.7 、 0.9 、 1.1$ \\
Test Temperature $/{ }^{\circ} \mathrm{C}$ & $40 、 50 、 60$ \\
Test termination & $\mathrm{N}=10000$ or $5 \%$ \\
& $(\mathrm{NCHRP9}-19)$ \\
\hline
\end{tabular}

(2) Triaxial repeated loading permanent deformation test method

The test specimens were kneaded and formed by the rotary compactor SGC rotary compactor, and the mixture specimens were formed into cylindrical specimens of $\phi$ $150 \mathrm{~mm} \times 175 \mathrm{~mm}$, and then cored and cut with a $\phi 100$ water drill to obtain a cylindrical test piece of $\phi 100 \mathrm{~mm}$ $\times 150 \mathrm{~mm}$. Finally, use sandpaper to polish to ensure that the surface unevenness of the test piece does not exceed $0.05 \mathrm{~mm}$. Place the test specimen at the corresponding test temperature for at least $5 \mathrm{~h}$ but not more than $10 \mathrm{~h}$. Ensure that the temperature inside and outside of the specimen reaches the predetermined test temperature. Set the test parameters and start the test based on test plan requirements.

\section{Results and analysis}

\subsection{The influence of temperature on permanent deformation}

Since the permanent deformation under other deviator stresses is consistent with the change rule under the standard tire pressure of $0.7 \mathrm{MPa}$, for the convenience of comparison, only $0.7 \mathrm{MPa}$ is used as an example for illustration. It can be seen from Figure 1 and Figure 2 that the permanent deformation at different temperatures: as the number of loading increases, the permanent deformation of SBS and LM-S modified asphalt mixtures will continue to increase, which means the more equivalent axes act on the road surface, the greater of permanent deformation of the pavement is, because a load must produce a certain amount of permanent deformation each time, the road surface actually shows the permanent deformation accumulated under a certain axis; the higher the temperature is, the greater the permanent deformation could be, and when the temperature exceeds $50{ }^{\circ} \mathrm{C}$, the permanent deformation will increase sharply and the specimen will be destroyed quickly in a short time. That is to say, temperature has a huge influence on permanent deformation. The higher the temperature, the greater the permanent deformation. This is due to the increase of temperature and the softening of cement, which makes the specimen easy to damage, especially when the temperature is close to the softening point of cement. Permanent deformation will increase rapidly until it breaks.

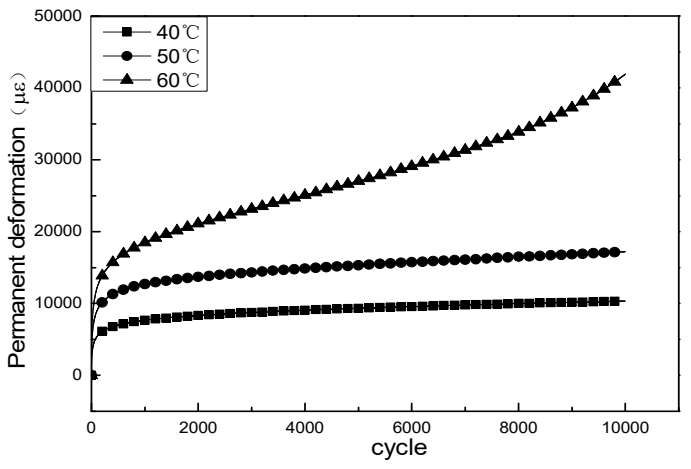

Figure 1. Permanent deformation of SBS@0.7MPa 


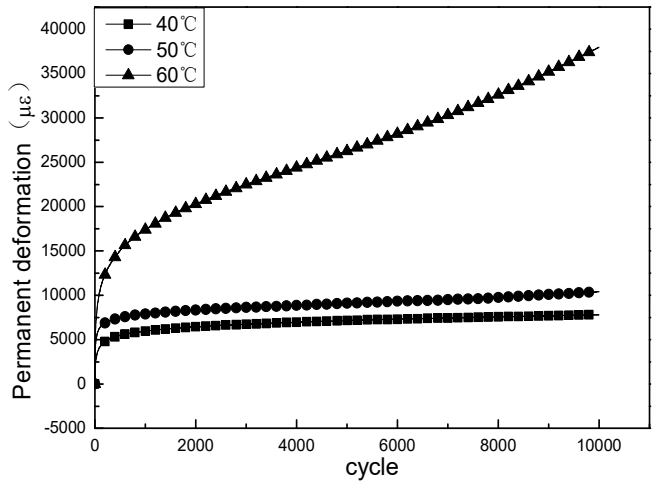

Figure 2. Permanent deformation of LM-S@0.7MPa

\subsection{The influence of deviator stress on permanent deformation}

Also because the permanent deformation at other temperatures is basically the same as the change at $40^{\circ} \mathrm{C}$ (only the third stage will appear in the permanent deformation curve of the mixture at higher temperatures) for the convenience of comparing the effect of deviator stress on the axial permanent deformation. Only take $40^{\circ} \mathrm{C}$ as an example. It can be seen from Figures 3 and 4 that the permanent deformation under different deviator stresses: as the number of loading increases, the permanent deformation of both SBS and LM-S modified asphalt mixtures will continue to increase, which is the same as the previous. The greater the deviator stress is, the greater the permanent deformation will be. When the deviator stress is $0.7 \mathrm{MPa}$, the permanent deformation curve is smooth. When the deviator stress reaches 1.1 $\mathrm{MPa}$, the slope of the permanent deformation curve increases significantly compared with $0.7 \mathrm{MPa}$. Which means that the greater the axle load is, the greater the permanent deformation will be. This is because the asphalt mixture is a viscoelastic material, the axial strain will increase with the increase of stress, and the irreversible permanent deformation of the material with large strain will also be greater. In the end, a larger deviator stress shows a larger axial permanent deformation.

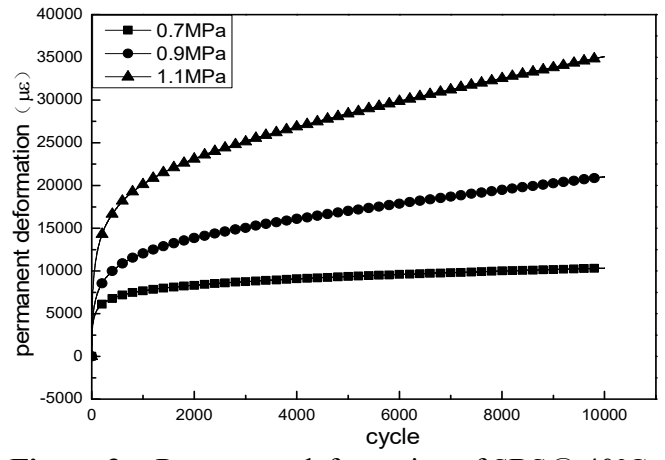

Figure 3. Permanent deformation of SBS@ $40^{\circ} \mathrm{C}$

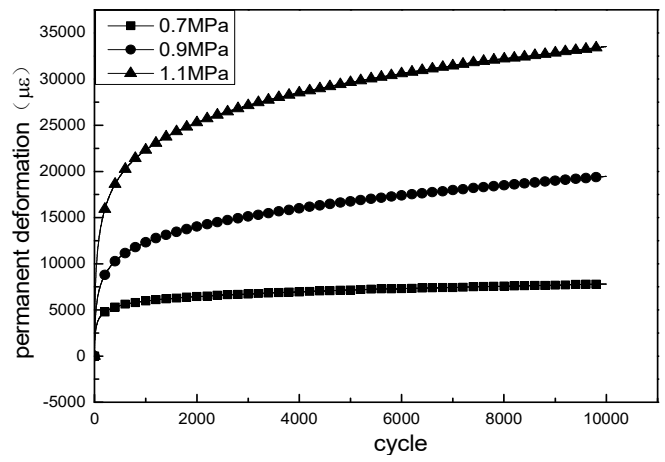

Figure 4. Permanent deformation of LM-S@ $40^{\circ} \mathrm{C}$

\subsection{Comparison of high-temperature performance of SBS and LM-S modified asphalt mixture}

(1) Comparison of permanent deformation

Since the permanent deformation change rule under the combination of standard tire pressure $0.7 \mathrm{MPa}$ with $40^{\circ} \mathrm{C}$ and the combination of $1.1 \mathrm{MPa}$ with $50^{\circ} \mathrm{C}$ can represent the test results under all other combinations, for the convenience of comparison, only take $0.7 \mathrm{MPa}-40^{\circ} \mathrm{C}$ and $1.1 \mathrm{MPa}-50^{\circ} \mathrm{C}$ as examples to illustrate. It can be seen from the permanent deformation of the two asphalt mixtures in Figures 5 and 6: The permanent deformation of LM-S modified asphalt mixture is less than that of SBS modified asphalt mixture, and the greater of both temperature and deviator stress, the more significant effect can be shown. This indicates that the permanent deformation resistance of LM-S modified asphalt mixture is stronger than that of SBS. It is said that LM-S modified asphalt mixture is more advantageous than SBS in hightemperature areas and large axle load sections.

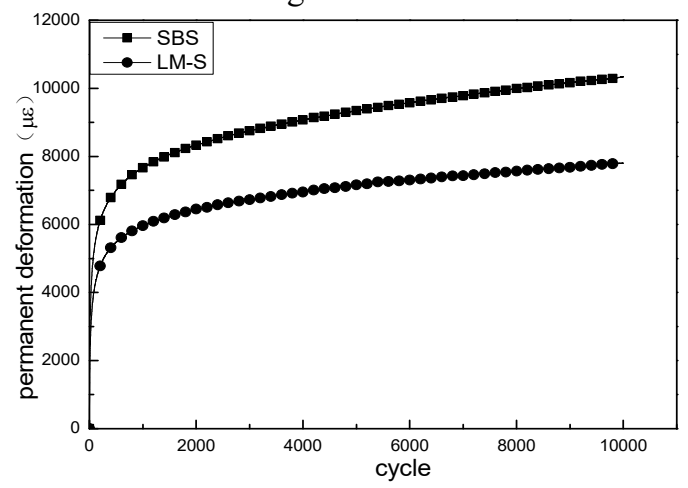

Figure 5. Permanent deformation of asphalt mixture@

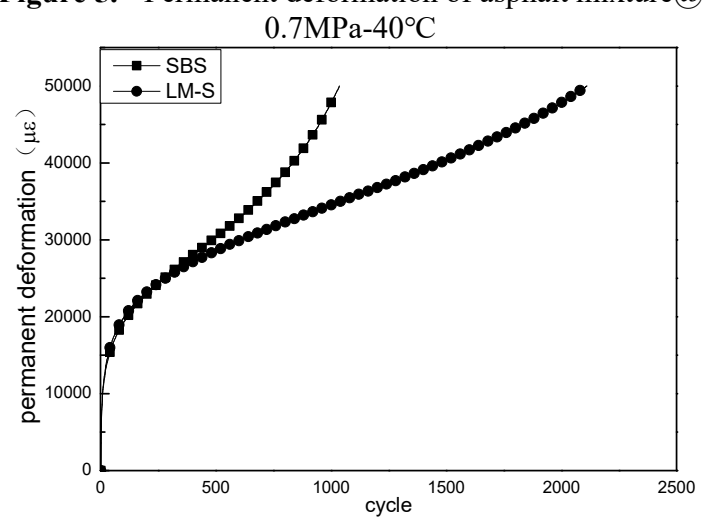

Figure 6. Permanent deformation of asphalt mixture@ $1.1 \mathrm{MPa}-60^{\circ} \mathrm{C}$ 
(2) The comparison on $\varepsilon @ 500$

The research results show that the accumulated permanent deformation of the repeated loading test under 5000 cycles can well reflect the high-temperature antideformation ability of the asphalt mixture. It can be seen from the two asphalt mixtures $\varepsilon @ 5000$ in Fig. 7 that: as the deviator stress increases, the $\varepsilon @ 5000$ of two kinds of asphalt mixtures are constantly increasing, the greater the deviator stress is, the greater the permanent deformation of the asphalt mixture after 5000 cycles is, which also shows that the deviator stress increases while the the asphalt mixture performance at high-temperature will decrease; at the same time, it is found that $\varepsilon @ 5000$ will increase as the temperature increases, which means that the high-temperature deformation resistance of asphalt mixture will also decrease when temperature rise. Observation found that the two asphalt mixtures ع@5000 can be strictly distinguished only at $50^{\circ} \mathrm{C}$. At $40^{\circ} \mathrm{C}$, it is difficult to accurately judge the high-temperature performance of the two asphalt mixtures $\varepsilon @ 5000$. At $60^{\circ} \mathrm{C}$, asphalt mixture will soon be destroyed under large deviator stress and $\varepsilon @ 5000$ even not exist. It is also difficult to determine the high-temperature performance of the asphalt mixture according to the size of $\varepsilon @ 5000$. This means that, only at $50^{\circ} \mathrm{C}, \varepsilon @ 5000$ can be used as evaluation indicator of the high- temperature performance, which will have a more obvious effect, and it is difficult to achieve in higher or lower temperatures.

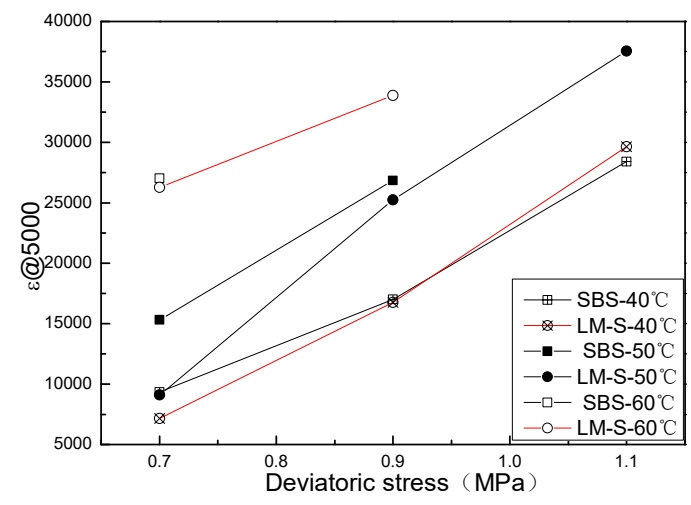

Figure 7. $\varepsilon @ 5000$ of asphalt mixture

\section{(3) Comparison of flow number FN}

The same research results show that for repeated loading tests with confining pressure, the flow number FN can be used as a basic index to evaluate the hightemperature performance of asphalt mixtures. It can be seen from the flow number FN of the two asphalt mixtures in Figure 8 that the flow number of the LM-S modified asphalt mixture is generally greater than that of the SBS under the same deviator stress and temperature combination, indicating that the high temperature of the LM-S modified asphalt mixture performance is better than SBS. With the increase of deviator stress, the flow number FN changes little at $40^{\circ} \mathrm{C}$, and basically does not change with the deviator stress, in other word, the flow number is not sensitive to the change of deviator stress at $40^{\circ} \mathrm{C}$. It becomes sensitive when the temperature reaches $50^{\circ} \mathrm{C}$ and the deviator stress goes to $0.9 \mathrm{MPa}$ or higher. When the temperature reaches $60^{\circ} \mathrm{C}$, the flow number $\mathrm{FN}$ decreases rapidly with the increase of deviator stress, which means that the flow number is very sensitive to the change of deviator stress. Although we can draw the conclusion that the flow number of LM-S modified asphalt mixture is generally greater than that of SBS, since the flow number FN at $40^{\circ} \mathrm{C}$ is as high as 9500 or more, and the test termination limitation is only 10,000 cycles, the results are obtained within 10,000 cycles. The flow number is often not the real flow number. This is also the reason that the flow number is concentrated at about 9500 times at $40^{\circ} \mathrm{C}$. At this time, the flow number cannot reflect the high-temperature performance of the actual road surface. While, at $60^{\circ} \mathrm{C}$, the specimen will be destroyed quickly when the deviator stress is large, the flow number is very small at this time and the variability is large, which also cannot reflect the high-temperature performance of the asphalt mixture.

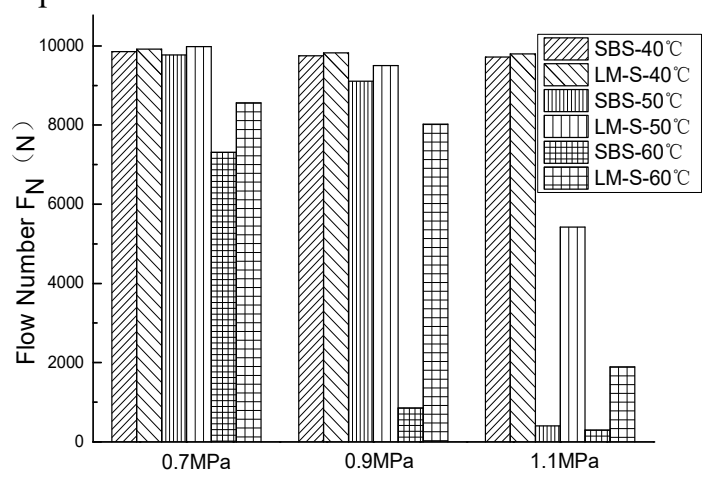

Figure 8. Flow number FN of asphalt mixture

(4) Comparison of creep rate

Creep rate has always been used as a basic indicator for evaluating high-temperature performance. From the creep rate of the two asphalt mixtures in Figure 9, it can be seen that with the increase of deviator stress, the creep rates of the two asphalt mixtures are increasing. When the temperature exceeds $50^{\circ} \mathrm{C}$ and the deviator stress reaches $0.9 \mathrm{MPa}$, the creep rate increases rapidly, indicating that deviator stress increases, fluidity of the asphalt mixture increases, while the ability of deformation resistance at high temperature decreases. At the same time, the higher the temperature is, the greater the creep rate is, that is to say that while the ability of deformation resistance in high temperature decreases when temperature increases. However, when the temperature reaches $60^{\circ} \mathrm{C}$ and the deviator stress exceeds $0.7 \mathrm{MPa}$, the SBS modified asphalt mixture will be quickly destroyed. The second stage is very short and it is difficult to accurately determine the corresponding creep rate. Under the same temperature and the same deviator stress, the creep rate of LM-S modified asphalt mixture is slightly lower than that of SBS, indicating that the deformation resistance of LM$\mathrm{S}$ modified asphalt mixture is slightly better than that of SBS modified asphalt mixture. This is because the binder viscosity of the LM-S modified asphalt mixture is slightly higher than that of the corresponding SBS, resulting in a stronger anti-deformation ability of the formed asphalt mixture, showing slightly better high-temperature performance than the SBS modified asphalt mixture. 


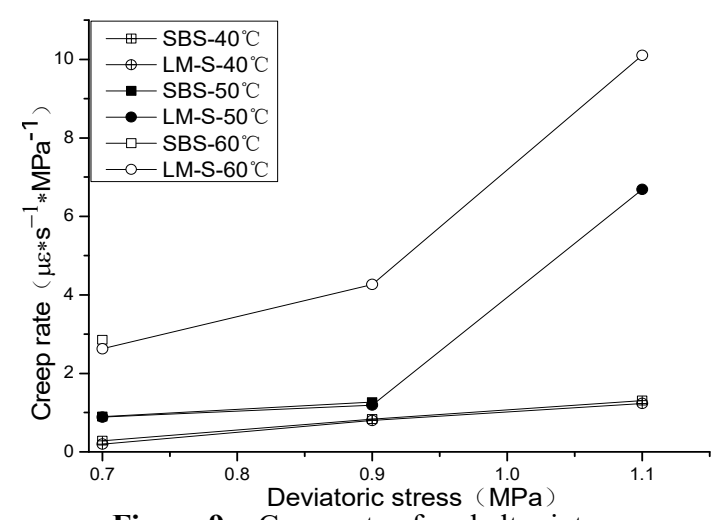

Figure 9. Creep rate of asphalt mixture

Through the evaluation of the high-temperature performance of the two asphalt mixtures by the different angle of four basic indicators: axial permanent deformation, $\varepsilon @ 5000$, flow number FN, and creep rate, the following can be concluded. The axial permanent deformation index reflects corresponding permanent deformation changing rules under different cycles. The changing law of deformation can significantly distinguish the permanent deformation of two kinds of asphalt mixtures in test condition, which can be considered as an excellent index to evaluate the high-temperature performance of asphalt mixtures. $\varepsilon @ 5000$ only takes accumulative permanent deformation corresponding to the first 5000 cycles, without considering the entire process of deformation; moreover, when the temperature and deviator stress are both large, the test specimen will be destoryed before reaching 5000 cycles, which means that the $\varepsilon @ 5000$ is not exist at all, so it is difficult to use this index to comprehensively measure the pros and cons of high-temperature performance of the two asphalt mixtures. Although the flow number FN exists in different conditions, but the largest number of loading cycles is 10,000 . The flow number FN under the combination of lower temperature and small deviator stress is very large or even more than 10,000 originally, the test instrument can only take the number of loading times corresponding with the minimum value of the current permanent deformation rate as the flow number FN in calculating. In fact, this value is very different from the real flow number. Therefore, if the flow number $\mathrm{FN}$ be chosen as the evaluation index of high-temperature performance, there will be the distortion problem under low temperature and small deviator stress. The creep rate uses the slope of the creep curve in the stable phase as the evaluation index. The curve in the stable phase changes smoothly, which can indirectly reflect the anti-deformation ability of the asphalt mixture to a certain extent. It has a certain objective representativeness, but similarly to $\varepsilon @ 5000$, when the temperature and deviator stress are both large, the test specimen will be destroyed immediately before entering the stable phase, or the stable phase is too short to get the accurate value of the creep rate, so the creep rate is difficult to fully measure the high-temperature performance of two asphalt mixture.

\section{Conclusion}

(1)For LM-S and SBS modified asphalt mixtures, the corresponding permanent deformation under different cycles can be observed by the axial permanent deformation any time, which can be used as an excellent index for evaluating the high-temperature performance of the two asphalt mixtures.

(2) The $\varepsilon @ 5000$ and creep rate under higher temperature and larger deviator stress are limited by conditions, so the corresponding value does not exist or is difficult to find. Both are not suitable to be directly used as an evaluation index, but these two are recommended in lower temperature and smaller deviator stress, especially the creep rate.

(3) The flow number FN, due to the limitation of conditions, leads to the distortion of the flow number under lower temperature and smaller deviator stress, but it has better representativeness under larger deviator stress and temperature conditions.

(4) Considering the two asphalt mixtures used in the study comprehensively, this article finally recommends the axial permanent deformation as a basic index for evaluating high-temperature performance.

(5) Different indicators of test show that the hightemperature performance of LM-S modified asphalt mixture is better than that of SBS modified asphalt mixture. It is recommended to use LM-S modified asphalt mixture instead of SBS modified asphalt mixture to improve anti-rutting ability of pavement.

\section{References}

1. DaquanSun, WeiminLu. Investigation and Improvement of Storage Stability of SBS Modified Asphalt[J]. Liquid Fuels Technology, 2003, 21(56):901-910.

2. DaquanSun, WeiminLu. Investigation and Improvement of Storage Stability of SBS Modified Asphalt[J]. Liquid Fuels Technology, 2003, 21(56):901-910.

3. ZHENG Chuan-feng, WANG Lei, XU Ya zhi, ZHANG Li, FU Ji Experimental Study on Recycled SBS Asphalt Mixture for use in Surface Course[J]. Journal of Civil Architectural\&Environmental Engineering, 2011,33(S1):143-147.

4. $\mathrm{Yu}$ Yin.SBS modified asphalt mixture performance $[\mathrm{J}]$. Jiangxi building materials 2016(10):152.

5. DaquanSun, WeiminLu. Investigation and Improvement of Storage Stability of SBS Modified Asphalt[J]. Liquid Fuels Technology, 2003, 21(56):901-910.

6. $\mathrm{Xu} \mathrm{S}, \mathrm{Yu} \mathrm{J}, \mathrm{Hu} \mathrm{C}$, et al. Laboratory evaluation of rejuvenation effect of reactive rejuvenator on aged SBS modified bitumen[J]. Materials \& Structures, 2017, 50(6):233. 
7. Hu Fang. The Study on Anti-aging Propertiesof SBS Modified asphalt[J]. Shanxi Communications Technology. 2012(05):17-19.

8. Wang Chunjiang. Star SBS modified asphalt research and industrial production application[J]. ShandongChemical Industry. 2016,45(08):70-72.

9. Lei Min. Impact on Rubber modifier of the Properties of asphalt and mixture[D]. Wuhan University of Technology, Wuhan University ofTechnology, 2014.

10. Li Guanlong, Study on the performance of SBS/LM$\mathrm{S}$ composite modified asphalt[D]. EastChina University of Science and Technology.2016

11. Wang Zhaohui, Fan Qiaojuan, Li Yanwei, et al. Effect of Mixing Process on Road Performance of Low-carbon Multi-functional Modified Asphalt Mixture [J]. Journal of China andForeign Highway;, 2016(6):234-238.

12. Fang H, Liu Q, Mo L, et al. Characterization of threestage rutting development of asphalt mixtures[J]. Construction \& Building Materials, 2017, 154:340348.

13. Guo Yanmei,Ni Fujian. Analysis of NonlinearViscoelastic Response of Modified Asphalt Based on Repeated Creep[J].Journal of BuildingMaterials, ,2013,16(05):908-912

14. He Changxuan, Fan Yinghua Triaxial Permanent Deformation Test of Asphalt Mixture in Repeated Loading[J].Highway, 2010(06):181-184.

15. Zhang Yuqing, Huang Xiaoming.Triaxial Repeated Load Creep Test and Study on Deformation Characteristics of Asphalt Mixture at High Temperature and Heavy Load [J] Highway 2006(12):151-156.

16. Yao H, You Z. Performance of Micro- and NanoModified Asphalt Mixtures Through Flow Number and Moisture Susceptibility Evaluations[J]. Journal of Testing \& Evaluation, 2017, 45(6):20150434.

17. Lu Hewei, Zhang Hongchao, Wang Jian, Guo Yinan. Research on Asphalt Mixture Stability at High Temperatures Applying MMLS3[J]. Journal of Building Materials, 2011,14(05):624-629.

18. Li Peilong, Zhang Zhengqi, Wang Binggang High Temperature Creep Deformation Behavior and its Mechanism of Asphalt Mixture[J].Journal of Building Materials,2012,15(03):422-426.

19. Li Zhaosheng, Tan Yiqiu, Wu Sigang, Yang Fuyu.The Effect of Freeze-thaw Cycle on Mechanical Properties of the Asphalt Mixture[J].Journal of Harbin Engineering University. ,2014,35(03):378-382.

20. Zhou Zhigang, Liu Xuguang, Luo Suping, ShaXiaopeng. Effect of Water intrusion on Performance of Asphalt Mixture[J].Journal of Central South University (Natural Science Edition), 2016,47(04):1359-1367. 